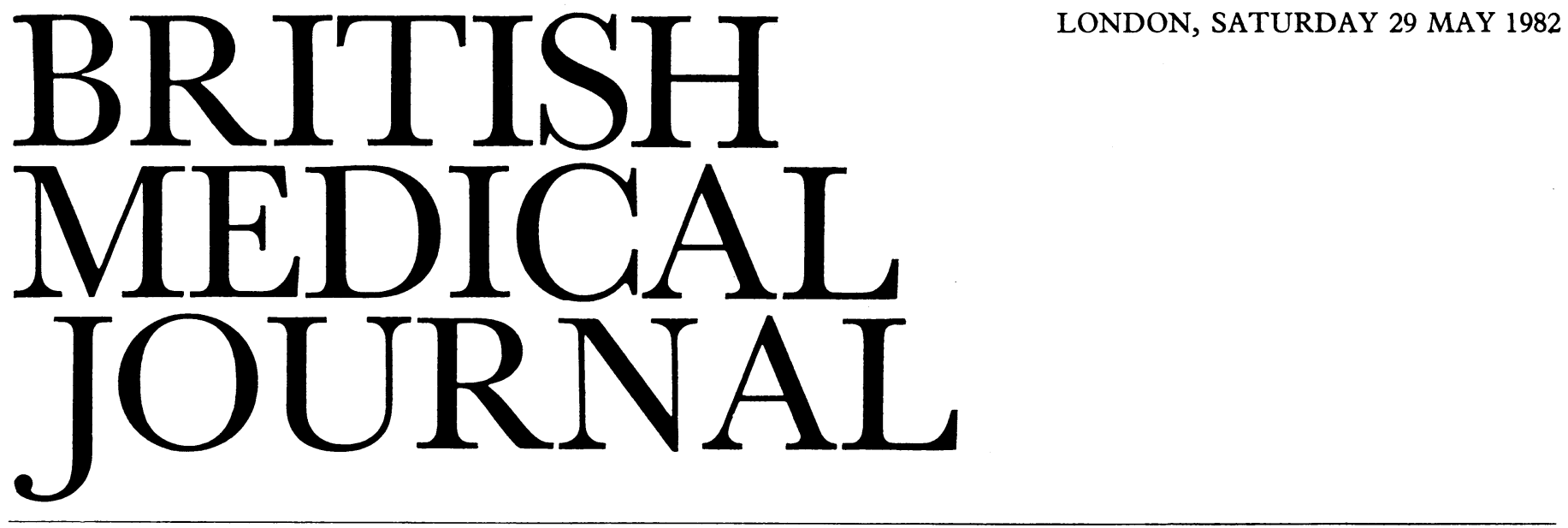

\title{
Toxic shock syndrome: some answers but questions remain
}

Two years have passed since the toxic shock syndrome was first reported in menstruating women in the United States. ${ }^{1}$ Subsequent elegant epidemiological investigations showed a definite association between the use of tampons and the development of the syndrome, and one brand (Proctor and Gamble's "Rely") was particularly implicated. Rely tampons were then withdrawn from the American market; they have never been sold in Britain. Many more cases of this severe multisystem disorder have since been reported, predominantly from the United States of America but also from elsewhere, and a mass of publications bears witness to the immense amount of research-microbiological, epidemiological, and toxicological-that has been undertaken.

By January 1981 a total of 941 confirmed cases of toxic shock syndrome had been reported to the Centers for Disease Control in the United States. ${ }^{2}$ The numbers had declined from September 1980 onwards, a trend which may have been associated with the withdrawal of Rely tampons from the market at that time and with a reduction in the use of tampons in general. The first reported case of toxic shock syndrome in Britain was in November $1980,{ }^{3}$ but no American style "epidemic" of the disease has occurred. ${ }^{4}$ An account of all 25 cases of toxic shock syndrome reported to the Central Public Health Laboratory, Colindale up to April 1982 appears at $\mathrm{p}$ 1641-figures which must have provided solace for worried manufacturers of tampons. Furthermore, this low figure for Britain is unlikely to represent underdiagnosis in view of the wide publicity accorded to toxic shock syndrome in both medical and lay circles. Indeed, retrospective diagnoses were made by doctors, ${ }^{5}$ by a medical student who recognised the syndrome recurring in herself, ${ }^{6}$ and even more impressively by a patient who contacted her medical attendants eight months after her original illness to suggest the diagnosis of toxic shock syndrome to them after she had seen a television programme. No mention was made of the original "medical" diagnosis. ${ }^{7}$

Though $99 \%$ of the confirmed cases of toxic shock syndrome reported to the Centers for Disease Control were in women, most of whom had developed it during a menstrual period, the disorder is not specific to menstruating women nor is it solely a "tampon disease," though understandably these aspects of its pathogenesis have received more attention than others. Toxic shock syndrome has occurred in the puerperium ${ }^{\text {}}$ and in association with the use of contraceptive diaphragms. ${ }^{6-11}$ It has even been reported in a married couple with simultaneous illnesses ${ }^{12}$ (a new sexually transmitted disease ?) and in a man who had recently cleaned out a lavatory obstructed with tampons. ${ }^{13}$ Reingold et al ${ }^{14}$ reported an increasing proportion of cases of toxic shock syndrome that were associated not with menstruation but with staphylococcal infections at a variety of sites that included the vagina. Moreover, the original description of toxic shock syndrome by Todd $e t$ al $^{15}$ was in children, three of whom were boys. These authors suggested that the syndrome was probably not new as similar disorders had been described previously in children in association with staphylococcal infection by Stevens in $1927^{16}$ and Aranow and Ward in 1942,17 and also in young women (two with axillary abscesses, one with a septic abortion) by Dunnet and Schallibaum. ${ }^{17 a}$ Toxic shock syndrome is thus emerging as a staphylococcal disease of multifactorial aetiology.

The strains of Staphylococcus aureus isolated from patients with toxic shock syndrome have been predominately phage group I, lysed by phage 29 and resistant only to penicillin. But evidence is accumulating to show that toxic shock syndrome is not produced by Staph aureus itself but by a toxin or toxins elaborated by the organism. The absence of bacteraemia in most cases would certainly support such a hypothesis, as would the acute onset, severity, and multisystem manifestations of the disorder. The original report by Todd et al ${ }^{15}$ of a new epidermolytic toxin in the strains of Staph aureus causing toxic shock syndrome has not been confirmed, but other toxins have now been isolated. In 1979 Schlievert et al ${ }^{18}$ purified a pyrogenic exotoxin produced by a strain of Staph aureus isolated from the vagina of a 20-year-old patient with what was thought to be Kawasaki disease but which in retrospect was almost certainly toxic shock syndrome. This toxin was shown to be distinct from other staphylococcal pyrogenic exotoxins and was designated staphylococcal pyrogenic exotoxin $C$ to distinguish it from previously described endotoxins $\mathrm{A}$ and B. Staphylococcal pyrogenic exotoxin $\mathrm{C}$ has a molecular weight of 22000 and an isoelectric point of $7 \cdot 2$.

Schlievert et al ${ }^{19}$ subsequently detected staphylococcal pyrogenic exotoxin $\mathrm{C}$ in all 28 strains that were tested from patients with toxic shock syndrome but also in five of 32 control strains. It is of interest that these five strains were from the vaginas of healthy women. At about the same time Bergdoll et $a l^{20}$ identified a new staphylococcal enterotoxin $\mathrm{F}$ in 61 of 65 strains of Staph aureus causing toxic shock syndrome. Subsequently in two "blind studies" they detected staphylococcal enterotoxin $\mathrm{F}$ in all 34 strains causing toxic 
shock syndrome and in three of 26 control strains; two of these latter strains were isolated from the vaginas of women with no history of toxic shock syndrome. This new enterotoxin has a molecular weight of 20000 and an isoelectric point of 6.8 and induced vomiting when injected intragastrically into monkeys.

Further studies on staphylococcal toxins have been undertaken by Barbour, ${ }^{21}$ who detected an extracellular protein with a molecular weight of 22000 and an isoelectric point of 7.0 in all of 15 strains causing toxic shock syndrome and half of 18 strains not causing the syndrome but isolated from the vagina. In Britain, de Saxe et $a l^{4}$ detected staphylococcal enterotoxin $\mathrm{F}$ in isolates from 10 of 12 patients with toxic shock syndrome and in $23 \%$ of 63 control strains, and they also found an extracellular protein band at 7.3 on isoelectric focusing in 10 of the 15 strains causing the syndrome. Whether or not all these toxins are the same is still not clear, nor has any been shown to be causative. Much remains to be elucidated.

Some other interesting theories have been propounded. Oskowitz ${ }^{22}$ has suggested that the pathogenesis of toxic shock syndrome may be related to prostaglandins, which seem to account for most of its clinical manifestations, while increased production of prostaglandins is known to occur in the endometrium at menstruation. He emphasises the need for circulating prostaglandins to be measured in patients with toxic shock syndrome.

Though toxic shock syndrome is clearly not only associated with tampons, the large number of cases that occurred in tampon users suggests some aetiological factor specific to tampon use and to Rely tampons in particular. Over the past few years synthetic "superabsorbent" materials have been incorporated into tampons, and microulcerations of the vagina have been shown to occur more often with the use of such tampons. ${ }^{23}$ Rely tampons contained carboxymethylcellulose fibre in a unique "teabag" construction, thus rendering them particularly occlusive and absorbent (and thus very popular with American women). Furthermore, this synthetic fibre, thought to be inert and insoluble, has recently been shown to be liquefied in vitro by the cellulase activity of many Gram-negative bacilli, ${ }^{24}{ }^{25}$ and microbial breakdown of carboxymethylcellulose might possibly occur in vivo. The relevance of this finding to the development of toxic shock syndrome is at present only speculative.

There is no justification at present for any suggestion that women should avoid using tampons, since the risk of developing toxic shock syndrome is extremely small. Equally unrealistic is the recent recommendation in a letter to the Lancet $^{26}$ (written by a man) suggesting that women should be instructed "at all times to exercise sparkling cleanliness handling or inserting tampons" and to avoid tampons when they have "infected pimples, paronychia, or a suspicion of a skin infection."

Predictably in view of the litiginous atmosphere that prevails in the United States an 18-year-old American girl who developed toxic shock syndrome has begun a two-milliondollar damages suit against Proctor and Gamble; 200 further cases have been filed. ${ }^{27}$

SUSANNAH J EYKYN

Reader in Clinical Microbiology,

St Thomas's Hospital,

London SE1 $7 \mathrm{EH}$

${ }^{1}$ Schrock CG. Disease alert. $¥ A M A 1980 ; 243: 1231$

2 United States Department of Health and Human Services/Public Health Service. Toxic-shock syndrome-United States, 1970-1980. Morbidity Mortality Weekly Report $1981 ; 30: 25-9$.
${ }^{3}$ Holt P. Tampon-associated toxic shock syndrome. $B r$ Med $\mathcal{F} 1981$;281 : $1321-2$

${ }^{4}$ de Saxe MJ, Wieneke AA, de Azvedo J, Arbuthnott JP. Staphylococci associated with toxic shock syndrome in the British Isles. Ann Intern Med (in press).

${ }^{5}$ Neild G, Cameron JS. Tampon shock. Lancet $1980 ;$;i:1196.

${ }^{6}$ Anonymous. Toxic shock and tampons. Br Med f 1980;281 :1426.

${ }^{7}$ Williams ER, Macpherson J. Retrospective self-diagnosis of toxic-shock syndrome. Lancet $1981 ; \mathrm{ii}: 1042-3$.

${ }^{8}$ Whitfield JW, Valenti WM, Magnussen R. Toxic shock syndrome in the puerperium. FAMA $1981 ; 246: 1806-7$.

${ }^{9}$ Loomis L, Feder HM Jr. Toxic-shock syndrome associated with diaphragm use. $N$ Engl $\mathcal{F}$ Med $1981 ; 305: 1585$.

10 Jaffe R. Toxic-shock syndrome associated with diaphragm use. $N$ Engl f Med 1981 ;305:1585-6.

${ }^{11}$ Lee RV, Dillon WP, Baehler E. Barrier contraceptives and toxic shock syndrome. Lancet $1982 ; \mathrm{i}: 221-2$.

12 Fisher CJ, Horowitz BZ, Nolan SM. The clinical spectrum of toxic shock syndrome. West $\mathcal{F}$ Med $1981 ; 135: 175-82$.

13 Tack KJ. Possible tampon-associated toxic shock syndrome in a man. Lancet $1981 ;$ ii : 1354

${ }^{14}$ Reingold AL, Dan BB, Shands KN, Broome CV. Toxic-shock syndrome not associated with menstruation. A review of 54 cases. Lancet 1982; $\mathrm{i}: 1-4$.

15 Todd J, Fishaut M, Kapral F, Welch T. Toxic-shock syndrome associated with phage-group I staphylococci. Lancet 1978 ;ii:1116-8.

${ }^{16}$ Stevens FA. Occurrence of Staphylococcus aureus infection with a scarlatiniform rash. $\mathcal{F} A M A$ 1927;88:1957-8.

17 Aranow $\mathrm{H} \mathrm{Jr}$, Wood WB Jr. Staphylococcic infection simulating scarlet fever. F $A M A$ 1942;119:1491-5.

17a Dunnet WN, Schallibaum EM. Scarlet-fever like illness due to staphylococcal infection. Lancet 1960;ii:1227-9.

${ }^{18}$ Schlievert PM, Schoettle DJ, Watson DW. Purification and physicochemical and biological characterization of a staphylococcal pyrogenic exotoxin. Infect Immun 1979;23:609-17.

19 Schlievert PM, Shands KN, Dan BB, Schmid GP, Nishimura RD. Identification and characterization of an exotoxin from Staphylococcus aureus associated with toxic-shock syndrome. F Infect Dis 1981;143: 509-16.

20 Bergdoll MS, Crass BA, Reiser RF, Robbins RN, Davis JP. A new staphylococcal enterotoxin, enterotoxin $F$, associated with toxic-shock syndrome Staphylococcus aureus isolates. Lancet 1981 ; i:1017-21.

21 Barbour AG. Vaginal isolates of Staphylococcus aureus associated with toxic shock syndrome. Infect Immun 1981 ;33:442-9.

22 Oskowitz SP. Toxic-shock syndrome. N Engl f Med 1981;304:1040.

${ }^{23}$ Friedrich EG Jr, Siegesmund.KA. Tampon-associated vaginal ulcerations. Obstet Gynecol 1980;55:149-56.

24 Tierno PM Jr. Cellulase activity of microorganisms on carboxymethylcellulose from tampons. Lancet 1981 ;ii:746-7.

${ }^{25}$ Hanna BA. Microbial degradation of carboxymethylcellulose from tampons. Lancet $1982 ; \mathrm{i}: 279$.

${ }^{26}$ Snelley WB. Preventing tampon-associated toxic shock. Lancet $1982 ; \mathrm{i}: 221$.

27 Thomas C. Doctor tells woman to avoid the coil. The Times 1982 ;Mar 5: $8(\operatorname{col} 7)$.

\section{Of woodchucks and men: the continuing story of hepatitis $B$ and hepatocellular carcinoma}

"The greatest intellectual prize ... a virologist can hope for is that some day he will be the first to explain ... the natural history of serum hepatitis." So wrote F M Burnet in 1962. ${ }^{1}$ Twenty years later many puzzles still remain, though there have been some notable advances, including most recently the discovery of the link between hepatitis B virus infection and the development of hepatocellular carcinoma. After the discovery of the Australia antigen, ${ }^{2}$ later shown to be a marker of the surface coat of the hepatitis B virus (hepatitis B surface antigen; $\mathrm{HBsAg}$ ), it soon became apparent that infection with hepatitis $\mathrm{B}$ virus is an antecedent rather than a complication of the development of a tumour ${ }^{3}$ and that areas of the world where the prevalence of $\mathrm{HBsAg}$ is high (up to $15 \%$ in some 